\title{
La responsabilidad de los empresarios por la seguridad de los productos de consumo
}

\author{
María Carolina Corcione ${ }^{1}$
}

\section{RESUMEN}

Los empresarios tienen diferentes obligaciones frente a los consumidores, dependiendo de si se trata de un problema de calidad de los productos que ofrecen en los mercados o si efectivamente se presenta un defecto en los mismos. Una vez se determina que se está en presencia de un producto defectuoso, el empresario tiene el deber de tomar una serie de acciones e informar a la autoridad competente para evitar que se cause un daño a la vida, la salud y/o la integridad de los consumidores. En este artículo se analizan esas acciones, las consecuencias de su omisión, así como el deber de información que tienen los empresarios ante la autoridad administrativa encargada de la protección de los derechos de los consumidores, una vez este conoce que uno de los bienes o servicios que puso a disposición del público es defectuoso.

Palabras clave: Producto defectuoso, Protección al consumidor, Seguridad en bienes de consumo, Garantía, Responsabilidad del empresario, Medida de recall.

1 Abogada de la Universidad Externado de Colombia, Bogotá, Colombia. Maestría en Derecho de la Università degli Studi di Roma "Tor Vergata", Roma, Italia. Gerente legal para Centroamérica y la región andina de Unilever, Bogotá, Colombia. Correo-e: mariacorcione@ yahoo.com Fecha de recepción: 10 de marzo de 2017. Fecha de modificación: 30 de marzo de 2017. Fecha de aceptación: 30 de mayo de 2017. Para citar el artículo: CorCiOnE, M. C. "La responsabilidad de los empresarios por la seguridad de los productos de consumo", Revista digital de Derecho Administrativo, n. ${ }^{\circ} 18$, segundo semestre, Universidad Externado de Colombia, 2017, pp. 255-284. DOI: https://doi.org/10.18601/21452946.n18.11 


\title{
Business' General Responsibility for Consumer Product Safety
}

\begin{abstract}
Businesses obligations towards consumers differ on account of whether it is a quality related problem or a defective or unsafe product one. Once it is determined that a product is unsafe or defective, businesses have the duty to implement a series of actions and to inform the Product Safety Agency, in order to prevent damages to the life, health and/or integrity of consumers. This paper examines measures taken by businesses once they are aware of the risks a defective or unsafe product raises, the consequences of their omission, and the reach of the information duty before the administrative authority in charge of protecting consumer's rights.
\end{abstract}

Keywords: Product Safety, Defective Product, Unsafe Product, Consumer Protection, Warranty, Business Liability, Recall Measures.

\section{INTRODUCCIÓN}

Desde que inició la producción industrial de bienes y la prestación masificada de servicios, el riesgo de que uno de los productos que se ponga en el mercado tenga un defecto que pueda poner en riesgo la vida o la integridad de los consumidores ha aumentado exponencialmente. Así, la asimetría de la que tanto se habla en la relación de consumo no debe entenderse únicamente en el sentido de que el empresario es el propietario exclusivo de la información que recibirá el consumidor o quien impone de forma unilateral y a veces arbitraria las condiciones del negocio jurídico, sino que este desequilibrio que motiva la creación de herramientas para proteger al consumidor también debe incluir la posibilidad de que uno de los productos a los cuales accede un consumidor tenga un defecto que lo pueda lesionar, le pueda causar la muerte e incluso pueda causarle daños que mermen su patrimonio ${ }^{2}$.

2 Ver Kenneth S. Abraham, The Forms and Functions of Tort Law, Foundation Press, 4. a ed., 2012, p. 216, citado por MARCELA TABAKIAN, "Evolución de la responsabilidad del fabricante en Estados Unidos y su influencia en el derecho comparado", Revista de Derecho de la Universidad de Montevideo, n. ${ }^{\circ}$ 26, 2014; Javier TAMAYO JARAmillo, Responsabilidad por producto defectuoso, Bogotá: Legis, 2016; CARlos Germán CAYCedo Espinel, "Esquema de la responsabilidad civil en el derecho de protección al consumidor en Colombia", en La responsabilidad civil en el nuevo Estatuto del Consumidor, Bogotá: Universidad Jorge Tadeo Lozano, 2013; ManueL JosÉ Cepeda EspinOSA, "La responsabilidad del fabricante por productos defectuosos (en el derecho comparado y la legislación colombiana)", Revista de Derecho Privado, n. ${ }^{\circ}$ 1, Universidad de los Andes, 1986, pp. 33-74, P. Cerami, A. Di Porto y A. Petrucci, Diritto commer- 
Para entender en qué consiste la protección al consumidor en materia de seguridad de productos de consumo en Colombia es necesario, en primer lugar, entender cuál es la fuente de la protección al consumidor frente a los productos., para luego explicar qué se entiende por producto inseguro o defectuoso, como lo ha denominado el legislador colombiano. Una vez realizada la explicación del concepto de producto inseguro o defectuoso se explicarán las obligaciones que nacen para los empresarios, y las facultades en cabeza de las autoridades administrativas y judiciales cuando se detecta un producto defectuoso en el mercado, así como cuando este ya ha causado un daño al consumidor.

\section{LA PROTECCIÓN DE LOS CONSUMIDORES FRENTE A LOS RIESGOS PARA SU SALUD Y SEGURIDAD}

La Constitución Política de Colombia en el artículo 78 señala que serán responsables, de acuerdo con la ley, quienes en la producción y en la comercialización de bienes y servicios atenten contra la salud y la seguridad de los consumidores $^{3}$.

Por su parte, el numeral 1 del artículo 1 de la Ley 1480 de 2011, también conocida como Estatuto del Consumidor (EC), señala que uno de los objetivos de la regulación en materia de protección al consumidor es "la protección de los consumidores frente a los riesgos para su salud y seguridad".

Dicha protección se encuentra materializada como derecho del consumidor. El legislador, en el numeral 1.2 del artículo 3 EC, decidió que el consumidor tiene derecho a "que los productos no causen daño en condiciones normales de uso y a la protección contra las consecuencias nocivas para la salud, la vida o la integridad de los consumidores".

Resulta de vital importancia resaltar que esta protección de la que goza el consumidor difiere de aquella que resulta de la vulneración del derecho a recibir productos de calidad, que según el numeral 1.1 del artículo 3 EC consiste

ciale romano: profilo storico, Torino: Giappichelli, 2004, Pedro Octavio Munar Cadena, "La responsabilidad por productos. Los grandes hitos de su evolución", en Derecho del consumo. Problemáticas actuales, de J. M. Gual Acosta, Bogotá: Jurídicas Gustavo Ibáñez, 2013, pp. 173 . 211; David Owen y Mary Davis. Products Liability and Safety, Minnesota: West Academics Publishing, 7. a ed. . José LuIs RodríGuez CarRión, "La responsabilidad civil por los daños causados por productos defectuosos", Revista General de Derecho, Valencia, 2000.

3 Constitución Política de la República de Colombia: "Artículo 78. La ley regulará el control de calidad de bienes y servicios ofrecidos y prestados a la comunidad, así como la información que debe suministrarse al público en su comercialización. Serán responsables, de acuerdo con la ley, quienes en la producción y en la comercialización de bienes y servicios, atenten contra la salud, la seguridad y el adecuado aprovisionamiento a consumidores y usuarios. El Estado garantizará la participación de las organizaciones de consumidores y usuarios en el estudio de las disposiciones que les conciernen. Para gozar de este derecho las organizaciones deben ser representativas y observar procedimientos democráticos internos". 
en el derecho a recibir el producto de conformidad con las condiciones que establece la garantía legal, las que se ofrezcan y las habituales del mercado.

La Corte Suprema de Justicia, Sala de Casación Civil, en sentencia del 30 de abril de 2009, con ponencia del magistrado Pedro Octavio Munar Cadena, señaló:

Así, el artículo 78 de la Carta Política de 1991 alude a dos esferas de protección disímiles, aunque complementarias, pero claramente definidas [...] Trátase pues, de una franca y rotunda alusión, de índole constitucional, a un régimen de responsabilidad de productores y distribuidores, derivado ya no de las deficientes o irregulares condiciones de idoneidad y calidad de los productos que manufacturan o mercantilizan, sino de los actos que lesionan la salud y seguridad de usuarios y consumidores. De esa perspectiva, esta última prescripción complementa y perfecciona el conjunto de salvaguardas de la parte débil de la relación de consumo.

En igual sentido, Javier Tamayo Jaramillo explica:

... mientras que la garantía de eficiencia busca que los bienes o servicios cumplan la finalidad para la cual fueron adquiridos, la responsabilidad por productos defectuosos regula la indemnización por los daños a la vida y a la integridad personal de terceros, así como la destrucción o deterioro de cosas, como consecuencia de un defecto en el diseño, fabricación, o presentación del producto ${ }^{4}$.

Por su parte, Carolina Zalamea Lechtman, en su tesis de maestría titulada La responsabilidad civil derivada de los productos defectuosos, señala que es muy importante no confundir

... la noción de defecto con la de eficiencia; esta última, lo que pretende es satisfacer al consumidor del producto en cuanto a los supuestos beneficios y objetivos para los cuales se compró el producto, pero si falla no genera un perjuicio material o lesión personal. Un claro ejemplo para esto es un shampoo que se promociona para que deje el pelo brillante y más sedoso; si al usarlo el pelo queda en el mismo estado, nos encontramos frente a un problema de eficiencia del producto. Por el contrario si ese mismo shampoo es usado por una persona y queda calva, nos encontramos sin duda, frente a un producto defectuoso ${ }^{5}$.

Juan Carlos Villalba, a su turno, en su obra Introducción al derecho del consumo, afirma: "Claramente se hace una diferencia entre producto defectuoso, noción

4 Javier Tamayo Jaramillo, "La responsabilidad civil en el nuevo Estatuto del Consumidor", disponible en: en http://www.utadeo.edu.co/files/node/publication/field_attached_file/ pdf-la_responsabilidad_civil_-web-_pag._16.pdf [consultado el 9 de septiembre de 2016].

5 Carolina Zalamea Lechtman, La responsabilidad civil derivada de los productos defectuosos, Colección de Maestrías n. ${ }^{\circ}$ 4, Bogotá: Pontificia Universidad Javeriana, Facultad de Ciencias Jurídicas y Grupo Editorial Ibáñez, 2014, p. 19. 
que está intrínsecamente relacionada con la seguridad, y producto no idóneo [...] por lo cual se definen claramente la independencia de los asuntos de la falta de idoneidad y la falta de seguridad". Y continúa explicando que en caso de idoneidad y calidad operarán las reglas relativas a la garantía del bien, mientras que "las reglas de responsabilidad civil por productos defectuosos solamente se aplican en caso de daños sufridos en la salud o integridad del consumidor o los bienes de éste" ${ }^{\prime \prime}$.

Así las cosas, tratándose de un problema de calidad, entendida como la condición en que un producto cumple con las características inherentes y las atribuidas por la información que se suministre sobre él ${ }^{7}$, o como un problema de idoneidad o eficiencia del producto, entendida esta como la aptitud del producto para satisfacer la necesidad o necesidades para las cuales ha sido producido o comercializado, el consumidor ${ }^{8}$ tendrá derecho a hacer efectiva la garantía legal o, en otros términos, a exigirle al productor y/o al proveedor que responda por el buen estado del producto y la conformidad del mismo con las condiciones ofrecidas.

Con lo anteriormente expuesto, planteemos el siguiente ejemplo: un consumidor compra una lavadora que además tiene la funcionalidad de secado según la información que le fue suministrada por el proveedor. El consumidor realiza la primera lavada e ilusionado, oprime el botón de secado notando que este no activa ninguna funcionalidad y que por lo tanto la ropa tendrá que extenderla al aire libre como habitualmente lo hacía. La lavadora tiene un problema de calidad e idoneidad, por lo que el consumidor está legitimado, de acuerdo con lo establecido por el Estatuto del Consumidor, para hacer efectiva la garantía del producto y exigir su reparación, su cambio o la devolución del dinero; y en caso de que esta reclamación no sea atendida, está facultado para ejercer la acción de protección al consumidor ${ }^{9}$ y presentar una demanda para que se cumpla la obligación de garantía a cargo del productor o proveedor.

Ahora, ¿qué pasa si al conectar la lavadora ocurre un corto circuito que hace que el electrodoméstico explote causándole la muerte al consumidor? ¿Se tratará de un simple problema de calidad que podrá ser reclamado por los herederos del consumidor fallecido a título de efectividad de la garantía? ¿Bastará que el productor y el proveedor reparen el bien, lo cambien o devuelvan el dinero? ¿Qué ocurre si hay en el mercado otras lavadoras que tienen el mismo problema?

Sin duda estamos ante escenarios diferentes que conllevan esquemas de responsabilidad y obligaciones para los empresarios que son totalmente distintas.

6 Juan Carlos Villalba Cuéllar, Introducción al derecho del consumo, Universidad Nueva Granada, 2012, pp. 231 y 232.

$7 \quad$ Art. 5 num. 1 de la Ley 1480 de 2011.

$8 \quad$ Art. 5 num. 6 de la Ley 1480 de 2011.

9 Art. 56 de la Ley 1480 de 2011 
En el ejemplo anteriormente planteado, no se trata de un simple problema de calidad, la lavadora puede tener un defecto que la hace insegura, por lo que es necesario que se aborde ahora el concepto de producto defectuoso o inseguro.

\section{LA DEFINICIÓN DE PRODUCTO DEFECTUOSO EN COLOMBIA}

\section{El Estatuto del Consumidor en el numeral 17 del artículo 5 define como pro- ducto defectuoso aquel bien mueble o inmueble que en razón de un error en el diseño, fabricación, construcción, embalaje o información no ofrezca la razonable seguridad a la que toda persona tiene derecho ${ }^{10}$.}

10 Esta definición no resulta del todo ajena a las definiciones que se manejan en otros países. En Estados Unidos, a comienzos del siglo xx, en el pronunciamiento Mac Pherson v. Buick, el juez Cardozo de la Corte de Nueva York, aunque menciona el concepto de negligencia del empresario, señala que un producto inminentemente peligroso es aquel que pone en peligro la vida o salud de una persona (Mac Pherson v. Buick Motor Co. 217 N.Y. 382, 111 N.E. 1050 (1916). Disponible en: https://www.nycourts.gov/reporter/archives/macpherson_buick. htm [consultado el 6 de septiembre de 2016]). Posteriormente, en 1972, en el caso Cronin v. J.B.E. Olson Corp., la Corte de California incluyó el concepto de uso razonable y previsible del producto para determinar si este tiene un defecto que pueda poner en riesgo la vida o integridad del consumidor. Adicionalmente, en este antecedente se trata el concepto de defecto referido a los casos de falta de información o advertencia, a los de instalación con negligencia y a los de diseño defectuoso. Disponible en: http://scocal.stanford.edu/opinion/ cronin-v-jbe-olson-corp-32939 [consultado el 6 de septiembre de 2016]. De acuerdo con Carolina Zalamea Lechtman, La responsabilidad civil derivada de los productos defectuosos, cit., p. 20, también se encuentra que el American Law Institute en la sección 4 del Restatement (Third) of Torts abandona el concepto de peligrosidad inminente del producto y clasifica los tipos de defecto que puede tener un producto en defectos de fabricación y de diseño, mencionando que estos últimos a su vez se clasifican en defectos de diseño en sí mismos y defectos de advertencia. Por otra parte, en el marco de la Unión Europea, la Directiva 85/374/CEE en su artículo 6 señala: "Un producto es defectuoso cuando no ofrece la seguridad a la que una persona tiene legítimamente derecho, teniendo en cuenta todas las circunstancias, incluso: a) la presentación del producto; $;$ ) el uso que razonablemente pudiera esperarse del producto; c) el momento en que el producto se puso en circulación. 2. Un producto no se considerará defectuoso por la única razón de que, posteriormente, se haya puesto en circulación un producto más perfeccionado". Así mismo, la Directiva 92/59/CEE, en el literal b) del artículo 2 , señala que por producto seguro se entenderá cualquier producto que, en condiciones de utilización normales o razonablemente previsibles, incluida la duración, no presente riesgo alguno o únicamente riesgos mínimos, compatibles con el uso del producto y considerados admisibles dentro del respeto de un nivel elevado de protección de la salud y de la seguridad de las personas, habida cuenta, en particular, de los siguientes elementos: - características del producto, y entre ellas su composición, embalaje, instrucciones para su montaje y mantenimiento $_{i}$ - efecto sobre otros productos cuando razonablemente se pueda prever la utilización del primero junto con los segundos; - presentación del producto, etiquetado, posibles instrucciones de uso y eliminación, así como cualquier otra indicación o información por parte del productor $;$ - categorías de consumidores que estén en condiciones de mayor riesgo en la utilización del producto, en particular los niños. La posibilidad de obtener niveles superiores de seguridad o de obtener otros productos que presenten menor grado de riesgo no será 
De igual forma, el legislador colombiano, en el numeral 14 del artículo 5 EC, definió seguridad como:

[La] condición del producto conforme con la cual en situaciones normales de utilización, teniendo en cuenta su duración, la información suministrada en los términos de la presente ley y si procede, la puesta en servicio, instalación y mantenimiento, no presenta riesgos irrazonables para la salud o integridad de los consumidores. En caso de que el producto no cumpla con requisitos de seguridad establecidos en reglamentos técnicos o medidas sanitarias se presumirá inseguro.

Se tiene entonces que un producto totalmente seguro es inexistente. Todos los productos del mercado implican un riesgo en su utilización. Sin embargo, hay riesgos que son irrazonables porque el consumidor ha hecho un mal uso del producto sin que este uso fuera previsible para el empresario, y hay riesgos que resultan irrazonables en razón de unas condiciones propias del producto.

Por su parte, la Corte Suprema de Justicia proporcionó una definición de producto defectuoso como aquel producto que:

... no ofrece la seguridad que legítimamente se espera de él, condición que, en consecuencia, se predica no por la falta de aptitud para el uso para el que fue adquirido, sino por no cumplir las condiciones de seguridad a que tiene derecho el público, excluyendo por supuesto, cualquier utilización abusiva. Vale decir, que se trata de un concepto que no guarda necesaria correspondencia con la noción de vicios de la cosa o ineptitud de ésta, o de ausencia de las calidades esperadas ${ }^{11}$.

Antes de entrar a explicar en qué pueden consistir los defectos o errores del producto, o como se ha denominado previamente, las condiciones propias del

razón suficiente para considerar que un producto es 'inseguro' o 'peligroso'. En España, en el texto refundido de la Ley General de Defensa de los Consumidores y Usuarios, el artículo 137 señala: "1. Se entenderá por producto defectuoso aquél que no ofrezca la seguridad que cabría legítimamente esperar, teniendo en cuenta todas las circunstancias y, especialmente, su presentación, el uso razonablemente previsible del mismo y el momento de su puesta en circulación. 2. En todo caso, un producto es defectuoso si no ofrece la seguridad normalmente ofrecida por los demás ejemplares de la misma serie. 3. Un producto no podrá ser considerado defectuoso por el solo hecho de que tal producto se ponga posteriormente en circulación de forma más perfeccionada". Por otra parte, en Brasil, el artículo 8 del Código de Defensa del Consumidor establece: "Los productos y servicios colocados en el mercado de consumo no presentarán riesgos a la salud o a la seguridad de los consumidores, con excepción de aquellos considerados normales y previsibles como resultado de su naturaleza y función, estando obligados los proveedores, en cualquier hipótesis, a suministrar las informaciones necesarias y adecuadas a su respecto. Párrafo único. Tratándose de producto industrial es responsabilidad del fabricante ofrecer las informaciones a que se refiere este artículo, a través de impresos apropiados que deben acompañar al producto".

11 Corte Suprema de Justicia, Sala de Casación Civil. Sentencia del 30 de abril de 2009, M.P. Pedro Octavio Munar Cadena, ref. $258993193992199900629-01$, p. 36. 
producto, es necesario diferenciar el concepto de producto inseguro o defectuoso del de producto nocivo o peligroso. Esta distinción resulta importante en la medida en que las reglas de responsabilidad y las obligaciones especialísimas para los empresarios surgen con ocasión de los primeros.

La Corte Suprema en la sentencia apenas referida continúa explicando:

... no sobra advertir, en todo caso, que la seguridad que el consumidor puede legítimamente esperar no se concibe en términos absolutos; de ahí que nadie pueda anhelar que objetos ineludiblemente peligrosos (un arma, un raticida, algunas herramientas, etc.) que por su propia naturaleza comportan un riesgo y como tales son dados a conocer al público, tengan el grado de seguridad del que esencialmente carecen. La obligación de seguridad cuyo incumplimiento genera el deber indemnizatorio de que aquí se trata es aquella a la que razonablemente se puede aspirar, como consecuencia quedan excluidas las situaciones en las que el carácter riesgoso del producto es aceptado o conocido por el público y debería, pues, serlo también por la víctima ${ }^{12}$.

Al respecto, Juan Carlos Villalba, en su artículo "La responsabilidad por producto defectuoso en el derecho colombiano", explica la diferencia entre producto defectuoso y producto nocivo o peligroso en los siguientes términos:

... hay una diferencia entre el concepto de producto defectuoso y el de producto nocivo, siendo este último el que por su naturaleza puede ocasionarle un daño al consumidor, mas no por conductas atribuibles al productor o proveedor del bien, por ejemplo, el tabaco o las bebidas alcohólicas. Por su parte, producto peligroso es el que puede provocar mayores daños por su naturaleza misma, por ejemplo, un cuchillo y un pesticida ${ }^{13}$.

Continúa explicando el autor:

... un producto peligroso no es defectuoso si se cumple con la debida información acerca de su correcto uso, de tal forma que ofrece la seguridad que cabe legítimamente esperar (Parra, 1999, pp. 501-502, citado por Barrientos, 2010, p. 119), por lo tanto, si es seguro no es defectuoso. Al respecto señalan Ruiz y Marín (2006) que la peligrosidad es una cuestión de facto. Normalmente el control frente a este tipo de productos nocivos o peligrosos en el mercado, consiste en un deber de advertencia obligatorio a cargo de los productores o proveedores del bien sobre su utilización, conservación y riesgos inherentes al consumo ${ }^{14}$.

12 Ibíd., p. 37.

13 Juan Carlos Villalba Cuéllar, "La responsabilidad por producto defectuoso en el derecho colombiano", Civilizar vol. 14, n. ${ }^{\circ}$ 27, Universidad Sergio Arboleda, 2014, pp. 22-24. Disponible en: http://revistas.usergioarboleda.edu.co/index.php/ccsh/article/view/179/163 [consultado el 6 de septiembre de 2016].

14 Ibíd 
Y explica:

... no obstante estar diferenciados los conceptos, un producto peligroso puede ser además defectuoso cuando presenta deficiencias de información sobre el peligro que conlleva su manipulación o no incorpora las indicaciones precisas sobre su utilización y a consecuencia de ello, le genera un daño al consumidor (Gutiérrez, 2011, p. 676). En todo caso, ya sea que se trate de productos nocivos, peligrosos, o incluso en la generalidad de los productos, cuando los riesgos sean previsibles, la obligación del productor será informar y advertir al consumidor sobre el riesgo y el debido empleo del bien, porque no advertirlo torna el producto además en defectuoso ${ }^{15}$.

Entonces, el concepto de peligrosidad o nocividad del producto responde a la naturaleza intrínseca del producto, y los riesgos que derivan de su utilización difícilmente resultarían imprevisibles o irrazonables, por lo que lo mencionado por Villalba Cuéllar guarda plena consonancia con lo establecido por el legislador colombiano en el artículo 25 EC, en donde se señala que "tratándose de productos que, por su naturaleza o componentes, sean nocivos para la salud, deberá indicarse claramente y en caracteres perfectamente legibles, bien sea en sus etiquetas, envases o empaques o en un anexo que se incluya dentro de estos, su nocividad y las condiciones o indicaciones necesarias para su correcta utilización, así como las contraindicaciones del caso".

Así, si se tuviera que acudir a un ejemplo sencillo para explicar la diferencia entre producto peligroso y producto defectuoso, un cuchillo de cocina resultaría muy útil. El cuchillo de cocina por su naturaleza es peligroso, por su propia composición puede ocasionarle un daño al consumidor si no es usado en la forma que previsiblemente se espera y atendiendo la información y las advertencias que han sido suministradas por el empresario. Ahora, si un consumidor emplea razonablemente el cuchillo y cuando está cortando un alimento la hoja de metal se desprende del mango intempestivamente ocasionándole cortaduras, estamos ante un producto peligroso que a su vez es inseguro o defectuoso.

Hecha esa diferenciación, y retomando el concepto de producto defectuoso que trae el Estatuto del Consumidor, dispuso también el legislador que esta definición únicamente aplica a los bienes muebles o inmuebles y que el defecto puede consistir en un error en el diseño, fabricación, embalaje o información que se suministra del producto.

Lo primero que se debe advertir es que, conforme lo estableció el legislador colombiano, no existen servicios defectuosos: la definición está restringida a los bienes muebles e inmuebles. Sin embargo, la inclusión de los servicios dentro de la categoría de productos defectuosos es un tema polémico a nivel 
global. Sin querer ahondar en la explicación, en el Consumer Product Safety Act de Estados Unidos, su sección 3 de definiciones no incluye a los servicios ${ }^{16}, \mathrm{y}$ la Directiva 92/59/CEE pareciera únicamente referirse a los bienes. Pero, si se revisan, por ejemplo, instrumentos internacionales en materia de seguridad de producto, como los que se expiden en el seno de la Organización para la Cooperación y el Desarrollo Económico (OCDE), en la Decisión Recomendación del Consejo del Sistema de Notificación de Medidas en Materia de Seguridad de Producto (C(89)106/FINAL) se encuentra que se deberán reportar los defectos o problemas de seguridad de los servicios auxiliares claramente relacionados con un producto de consumo o la instalación de un producto de consumo, tales como instrucciones de uso, instalación y mantenimiento del producto ${ }^{17}$. Igual ocurre en Australia, cuya ley de consumo incluye en su regulación de seguridad de producto a los "product-related services" 18 .

Ahora, el siguiente interrogante surge frente a los bienes y la inclusión de los inmuebles en la definición de producto defectuoso. La Corte Suprema de Justicia, en la mencionada sentencia del 30 de abril de 2009, destacó que en materia de responsabilidad por producto defectuoso el ámbito estaba restringido a los bienes muebles ${ }^{19}$, y así ocurre en las legislaciones internacionales apenas referidas.

Adicionalmente, tratándose de bienes muebles, la definición que plantea el legislador colombiano es muy amplia. No se sabe con certeza si están incluidos todos los bienes muebles del mercado que presenten alguno de los 'errores' mencionados, situación que resulta ambiciosa si se compara con legislaciones de países más desarrollados donde claramente se hacen distinciones y exclusiones en el ámbito de aplicación de las normas generales de seguridad de producto. Es usual en el mundo que la autoridad de consumo no conozca de medicamentos y alimentos defectuosos o inseguros, y que se excluyan igualmente del conocimiento de la misma autoridad los vehículos y los dispositivos médicos inseguros. Sin embargo, en la legislación colombiana parece no existir tal diferenciación, pues el legislador habla en general de los bienes muebles e inmuebles que tengan un defecto.

Ahora bien, habiendo hecho la diferenciación de lo que es un producto inseguro o defectuoso y de lo que es un producto nocivo o peligroso, y habiendo

16 United States Consumer Product Safety Act (Codified at 15 usc 2051-2089) Public Law 92-573; 86 Stat. 1207, Oct. 27, 1972. Disponible en: http://www.cpsc.gov/PageFiles/105435/cpsa. pdf?epslanguage $=$ en [consultado el 6 de septiembre de 2016].

$17 \mathrm{http}$ //acts.oecd.org/Instruments/ShowInstrumentView.aspx? InstrumentID=186\&Instrum entPID $=182 \&$ Lang $=$ en [consultado el 6 de septiembre de 2016].

$18 \mathrm{https} / /$ www.accc.gov.au/business/treating-customers-fairly/product-safety\#product-safetyregulation [consultado el 6 de septiembre de 2016].

19 Corte Suprema de Justicia, Sala de Casación Civil. Sentencia del 30 de abril de 2009, M.P. Pedro Octavio Munar Cadena, cit., p. 31. 
aclarado que en la definición del Estatuto del Consumidor solo están incluidos los bienes muebles e inmuebles, excluyendo los servicios, es necesario ahora hablar de cada uno de los tipos de 'errores' que se plantean en la definición legal de producto defectuoso, esto es, error en el diseño, en la fabricación, en la construcción, en el embalaje o en la información.

Una crítica válida frente al concepto de 'error' que se incluye en la definición legal de producto defectuoso la plantea Villalba Cuéllar al afirmar:

Al respecto surge una crítica al concepto colombiano, porque se centra en la idea de error y no en la de defecto, que se ata a la noción de seguridad en la mayoría de ordenamientos jurídicos. En efecto, si el error es un "concepto equivocado o juicio falso" o una "acción desacertada o equivocada", según el Diccionario de la Real Academia Española, hacer girar la noción de producto defectuoso en torno al significado de error, implica dotarla de una subjetividad que no merece, y acercarla a la idea de falla humana, con tintes de responsabilidad por culpa, lo cual resulta inadmisible ${ }^{20}$.

Teniendo en cuenta lo anterior, sería más acertado hablar de tipos de defecto del producto.

Bien se les denomine errores o defectos, el Estatuto del Consumidor, en el numeral 17 del artículo 5, se limita a enlistar los posibles tipos de defecto, sin que el legislador los desarrolle posteriormente en el articulado de la ley ${ }^{21}$. De ahí que se acuda a la doctrina para entender en qué consisten.

Doctrinariamente el defecto en la fabricación ocurre cuando el producto no está conforme a las especificaciones de diseño o no cumple los estándares de desempeño o se desvía de manera sustancial de otras unidades idénticas de la misma línea de productos. Los defectos de fabricación pueden resultar de un ensamblaje inadecuado, partes faltantes, partes sueltas o mal ensambladas, partes averiadas, o del uso de materiales de baja calidad por debajo de los estándares o bien que son defectuosos ${ }^{22}$.

Villalba Cuéllar explica que los errores de fabricación son:

20 Juan Carlos Villalba Cuéllar, La responsabilidad por producto defectuoso en el derecho colombiano, cit., p. 23.

21 Salvo que se forzara la interpretación según la cual un error en la información ocurre cuando se incumple la obligación general contenida en el artículo 23, que consiste en suministrar a los consumidores información clara, veraz, suficiente, oportuna, verificable, comprensible, precisa e idónea sobre los productos que se ofrezcan. Sin embargo, esta interpretación resulta equívoca en materia de seguridad de producto.

22 Denis W. STAERN, "An introduction to product liability", disponible en: http://www.marlerclark.com/pdfs/intro-product-liability-law.pdf" [consultado el 6 de septiembre de 2016]: "Manufacturing Defects: A product is considered to bave manufacturing defect any time that it does not conform to design specifications or performance standards, or it deviated in some material way from otherwise identical units of the same product line. Manufacturing defects like these can result from improper assembly, missing parts, loose parts, warped parts, or the use of substandard or otherwise defective materials. In the 
... los que pueden surgir en un problema de producción, tales como aquellos debidos al mal funcionamiento de una máquina o un yerro humano y que generan un defecto en una serie de producción. La doctrina insiste en que estos defectos pueden afectar algunos ejemplares de una serie, siendo el resto de la producción correcta (Gutiérrez, 2011, p. 678). En tercer lugar problemas de construcción para el caso de inmuebles, en los cuales un vicio de construcción da lugar a este tipo de responsabilidad. En cuarto lugar, problemas de embalaje o empaquetamiento que afecten la debida preservación del bien o alteren sus características de modo que se vuelva inseguro; y en quinto lugar, problemas de información, evento en el cual los riesgos previsibles de daño que presenta el producto pueden reducirse o evitarse mediante informaciones o advertencias razonables y su omisión convierte el producto en inseguro (Coderch et al., 2002, p. 17) ${ }^{23}$.

Para Velandia Castro, los defectos de fabricación son "los que se presentan o tienen origen dentro de la etapa de producción. Puede ser sobre toda la serie o sobre un solo ejemplar de la serie. Están asociados a la falta de control de calidad. El productor asume ese riesgo interno de producción"24.

Frente a los defectos en el diseño, Villalba Cuéllar plantea que se configura este tipo de defecto cuando

... todos los productos de la serie o modelo, sin excepción alguna, han sido mal ideados o proyectados de tal suerte que resultan peligrosos (Coderch et al., 2003, p. 15). Para Coderch et al. (2003) hay dos criterios para determinar si existe un defecto de diseño, primero el test de las "expectativas razonables del consumidor" -acogido en el derecho comunitario europeo y la ley española-, según el cual un producto está defectuosamente diseñado cuando defrauda las expectativas razonables del consumidor y lo lleva a error causándole daño. Segundo, el riesgo-utilidad -aceptado en las cortes estadounidenses-, que estima un diseño defectuoso cuando los riesgos previsibles de daño que presenta el bien podrían haber sido reducidos con la adopción de un diseño alternativo, razonablemente viable y más seguro (p. 15; este tema lo explican ampliamente Owen, Madden \& Davis, 2000 pp. 443-500). En armonía con Borghetti (2004) esta teoría del riesgo-utilidad, influenciada por la escuela del análisis económico del derecho, la recogieron los jueces norteamericanos, para los cuales se asumió que "un comportamiento es irrazonable y por lo tanto culpable cuando el costo de los daños que pudiese provocar, ponderado por la probabilidad de su ocurrencia, es superior al costo de las precauciones que hubieran podido evitar su ocurrencia" (p. 54). Estos dos criterios obedecen a de-

case of food products, a manufacturing defect can result, for example, when a potentially bazardous food is not cooked to the proper temperature, or when contaminated ingredients are used when the food is prepared". Juan Carlos Villalba Cuéllar, La responsabilidad por producto defectuoso en el derecho colombiano, cit., p. 26.

24 Mauricio Velandia Castro, "Acciones derivadas de las fallas en los productos (garantía legal, comercial y producto defectuoso", en Perspectivas del derecho del consumo, Bogotá: Universidad Externado de Colombia, 2013, p. 516 
sarrollos doctrinales y judiciales, y la ley colombiana no se refiere a ellos, por lo tanto, queda en expectativa el dictamen que se adopte ${ }^{25}$.

Zalamea Lechtman, citando el Restatement (Third) of Torts estadounidense, explica que la doctrina norteamericana considera que hay defecto de diseño "cuando los riesgos previsibles del daño ocasionado por el producto pudieron haber sido reducidos o evitados con la adopción de un diseño razonable alternativo, por el vendedor u otro distribuidor, o un antecesor en la cadena comercial de distribución, y la omisión del diseño alternativo hace que el producto no sea razonablemente seguro" ${ }^{\prime 26}$.

Continúa explicando la autora en cita que para que exista un diseño seguro de un producto se debe tener en cuenta los posibles usos y malos usos del producto, y se podrá también establecer que existe un defecto de diseño "probando que al menos hipotéticamente existe un diseño alternativo más seguro que el original, igual de económico en su producción que el original y tan práctico como el original, que mantenga el propósito primario que se encontraba detrás del primer diseño a pesar de los cambios realizados ${ }^{\prime \prime 2}$.

Para Velandia Castro, los defectos de diseño son "los relacionados con la parte de los planes técnicos previos a la fabricación o en la escogencia de los elementos para la fabricación del producto" ${ }^{\prime 28}$.

Tratándose de los defectos por advertencia o información, Zalamea Lechtman plantea que hay un producto defectuoso por un defecto de advertencia o información "cuando existe insuficiencia en las instrucciones o advertencias de los riesgos previsibles, los cuales se pueden reducir o evitar por instrucciones o advertencias razonables dadas por el vendedor, por el distribuidor o por un predecesor en la cadena comercial de distribución" ${ }^{\prime 29}$. Y continúa explicando:

... en este caso se está frente a riesgos que han podido ser reducidos o evitados con advertencias o instrucciones de uso, y la ausencia de estas instrucciones o advertencias hace que el producto no sea razonablemente seguro. La defectuosidad debe definirse conforme al uso o consumo normal del producto, de tal forma que en el evento en que un producto, por su naturaleza, pueda llegar a hacer creer a una persona que se le puede dar un uso diferente, y este uso diferente puede generar

25 Juan Carlos Villalba Cuéllar, La responsabilidad por producto defectuoso en el derecho colombiano, cit., p. 26.

26 Carolina Zalamea Lechtman, La responsabilidad civil derivada de los productos defectuosos, Colección de maestrías n. ${ }^{\circ}$ 4, Pontificia Universidad Javeriana, Facultad de Ciencias Jurídicas y Grupo Editorial Ibáñez, 2014, pp. 23 y 24.

27 Ibíd., p. 24.

28 Mauricio Velandia Castro, "Acciones derivadas de las fallas en los productos (garantía legal, comercial y producto defectuoso", cit., p. 516.

29 Carolina Zalamea lechtman, La responsabilidad civil derivada de los productos defectuosos, cit. p. 26. 
un daño material o una lesión personal, el producto deberá tener la advertencia de peligro ${ }^{30}$.

Villalba Cuéllar señala que en este último caso

... el producto no tiene un defecto, pero a causa de una indebida información al consumidor acerca del modo de utilización, contraindicaciones o advertencias, el consumidor sufre perjuicios en su integridad o en sus bienes. Es más, en casos especiales el defecto puede recaer en circunstancias particulares del consumidor (warning defects), hipótesis en la que el bien no tiene un defecto pero puede ser inseguro para ciertas personas, verbigracia, un alimento o medicamento que puede motivar una reacción alérgica a algunos sujetos. Este problema se corrige preventivamente a través de un deber de advertencia calificado que pesa a cargo del productor (Woolcott 2007, b, p. 121) ${ }^{31}$.

Velandia Castro explica que existe un defecto en la información "cuando el fabricante no comunica las instrucciones para el uso del producto, contraindicaciones y cuando adelanta afirmaciones falsas. Es importante denotar que de acuerdo con la definición legal, no solo se castiga el defecto del producto, también se castiga el defecto en la información, bien sea un defecto por acción u omisión en la información" ${ }^{\prime \prime 2}$.

Ahora, frente a los defectos de construcción, podría afirmarse que se pueden equiparar a los defectos de fabricación y de diseño e incluso atreverse a afirmar que está reservado para los inmuebles, pero esto es solo una interpretación personal. Igual ocurre con los defectos de embalaje, donde cabe preguntarse si se trata de un defecto de fabricación o de diseño del empaque del producto.

\section{LA RESPONSABILIDAD DE LOS EMPRESARIOS POR LA SEGURIDAD DE LOS PRODUCTOS DE CONSUMO}

Se ha dicho hasta este punto que la responsabilidad por la seguridad de los productos supera la obligación de asegurar la calidad de estos y de hacer efectiva la garantía. Igualmente, se ha explicado qué es un producto defectuoso y en qué puede consistir el defecto. Ahora, cabe preguntarse qué debe hacer el empresario cuando un producto defectuoso ocasiona un daño a la vida o integridad del consumidor o tiene la potencialidad de ocasionarlo. Así mismo,

30 Ibíd.

31 Juan Carlos Villalba Cuéllar, ob. cit., p. 26.

32 Mauricio Velandia Castro, "Acciones derivadas de las fallas en los productos (garantía legal, comercial y producto defectuoso", cit., p. 516. 
cabe cuestionarse qué debe hacer el consumidor que ha sufrido estos perjuicios como consecuencia de un defecto del producto.

Retomando el ejemplo del corto circuito que hace que la lavadora explote causándole la muerte al consumidor, se determina que el problema eléctrico se da porque se ensambló mal una pieza en la línea de producción del lote $\mathrm{X}$ de lavadoras. En este ejemplo, la lavadora es un producto defectuoso porque tiene un defecto en su fabricación que no ofrece la razonable seguridad a la que toda persona tiene derecho. Igual ocurre con todas las lavadoras del lote $\mathrm{X}$ que ya han sido vendidas en su totalidad. ¿Qué debe hacer el empresario?

Dispone el artículo 19 EC:

... cuando un miembro de la cadena de producción, distribución y comercialización, tenga conocimiento de que al menos un producto fabricado, importado o comercializado por él, tiene un defecto que ha producido o puede producir un evento adverso que atente contra la salud, la vida o la seguridad de las personas, deberá tomar las medidas correctivas frente a los productos no despachados y los puestos en circulación, y deberá informar el hecho dentro de los tres (3) días calendario siguientes a la autoridad que determine el Gobierno Nacional.

Entonces, ante el conocimiento de la ocurrencia de un accidente de consumo asociado a un producto, entendido como un evento en el cual el consumidor, usando razonablemente un producto, ve comprometida su vida o su salud, o ante el conocimiento de que un producto tiene la potencialidad de ocasionar un accidente de consumo por tener un defecto, el empresario (cualquier agente de la cadena de producción y comercialización que detente dicha información) deberá tomar medidas inmediatas para evitar que ese producto lesione a más consumidores, deberá decidir si hace una reingeniería del producto o lo retira del mercado (retoma o recall del producto) y deberá informar a la autoridad para contar con un acompañamiento y una orientación técnicas para replicar las medidas que se adopten frente a ese producto.

Este deber de información existe en países donde la seguridad de los productos que circulan en el mercado ha tenido un mayor desarrollo. En casi idénticos términos, la legislación canadiense (Canada Consumer Product Safety Act, Section 14), la estadounidense (Consumer Product Safety Act, Section 15), las normas supranacionales de la Unión Europea (Directiva 2011/95/CE del Parlamento Europeo y del Consejo de 3 de diciembre de 2011, relativa a la seguridad de los productos), e incluso instrumentos internacionales como la Recomendación de la OCDE relativa al procedimiento de recall para productos defectuosos asociados a productos vendidos al público ${ }^{33}$, consagran la obligación de informar entPID $=182 \&$ Lang $=$ en [consultado el 6 de septiembre de 2016]. 
a la autoridad acerca de la existencia de un producto defectuoso y de tomar medidas preventivas y correctivas frente al público consumidor.

El Gobierno Nacional, atendiendo el mandato del legislador, reglamentó el artículo 19 EC para establecer el procedimiento para informar una vez se tiene conocimiento de la existencia de un producto defectuoso. La reglamentación quedó contenida en el Decreto 679 del 27 de abril de 2016 (que adiciona el título 2 de la parte 2 del libro 2 del Decreto 1074 de 2015) y su redacción es congruente con las normas internacionales apenas transcritas, lo que acerca al país a estándares más rigurosos de seguridad de productos de consumo.

Vale la pena advertir que el decreto apenas mencionado hace una salvedad innecesaria cuando en su ámbito de aplicación indica que "no incluye a los productos que por su naturaleza son nocivos para la salud. Sin embargo, cuando estos presenten un defecto se someterán a la regla general" ${ }^{\prime 34}$.

De las definiciones planteadas en este artículo es apenas obvio que un producto nocivo por naturaleza no es inseguro o defectuoso salvo cuando se presente o se advierta el defecto. Esta redundancia contenida en el decreto podría dar lugar a confusiones para los empresarios colombianos que hasta este momento se están habituando a los temas de seguridad de productos de consumo.

Ahora, continuando con las obligaciones que surgen para los agentes de la cadena de producción y comercialización, lo primero que debe determinarse es cuándo un empresario tiene conocimiento de la existencia de un producto defectuoso que genera o puede generar un evento adverso para la salud de los consumidores. El artículo 2.2.2.52.2 del Decreto 1074 de 2015 señala que un miembro de la cadena de producción, distribución y comercialización tiene conocimiento de que un producto es defectuoso, entre otras situaciones, cuando:

1. Ha sido informado por un consumidor, por otro miembro de la cadena de producción, distribución o comercialización, o por un tercero, acerca de un bien que en situaciones normales de utilización, evaluando la duración del bien, la información suministrada (instrucciones, manuales, etc.) y, si procede, la puesta en servicio, instalación y mantenimiento, presenta riesgos irrazonables para la salud o integridad de los consumidores.

2. Conoce o cuenta con evidencias de que el producto podría incumplir con un requisito de seguridad o de inocuidad de un reglamento técnico o medida sanitaria o fitosanitaria que le sea exigible.

3. Conoce o cuenta con evidencias de que se está incurriendo en un error en el diseño, la fabricación, la construcción, el embalaje o la información del producto, de tal suerte que este no ofrezca la razonable seguridad a la que toda persona tiene derecho. 
4. Conoce o tiene noticia de que el estado de los conocimientos científicos y técnicos concluyen que el uso del producto involucra un riesgo de evento adverso a la salud, la vida o la integridad de los consumidores, o el producto no se encuentra conforme con uno o más requisitos de seguridad establecidos en normas técnicas internacionales vigentes.

5. Se inicie un proceso de investigación administrativa en el que se determine el momento en que el miembro de la cadena tuvo conocimiento de la existencia de un producto defectuoso.

6. Se haya informado en la jurisdicción de otro país sobre la existencia de un defecto en un producto.

Lo primero que debe indicarse es que el artículo apenas transcrito no contiene una presunción del conocimiento del defecto de un producto. Simplemente enlista una serie de hipótesis en las que el empresario, teniendo en cuenta su obligación de seguridad, puede estar poniendo en riesgo a sus consumidores y se le exige que adelante una serie de acciones.

Examinando las hipótesis de ocurrencia del conocimiento que enlista el decreto, existe una preocupación generalizada entre los empresarios frente al numeral primero del artículo apenas transcrito. Si un consumidor llama a la línea de atención al cliente a quejarse sobre un producto, ¿debo de una vez informar a la autoridad y tomar medidas preventivas y correctivas? Si un consumidor de mala fe anuncia en redes sociales que no está satisfecho con uno de mis productos porque le ocasionó una lesión, cestoy ante una hipótesis de producto defectuoso que desencadena las obligaciones especiales del Estatuto del Consumidor? ¿Se empiezan a contar los tres días para informar a la autoridad desde que recibo la llamada o la noticia por parte del consumidor?

La respuesta a todos los anteriores interrogantes es un "No" contundente. De hecho, sería irresponsable para el mercado que ante cualquier noticia del consumidor, los empresarios tuvieran que tomar medidas frente a sus productos o se considerara que automáticamente son inseguros. Lo que indica el numeral 1 del artículo transcrito es que si el empresario recibe noticia del consumidor de la ocurrencia de un accidente de consumo y evalúa que el bien fue usado razonablemente y aun así se le ocasionó al consumidor una lesión a su vida, su salud o su integridad, o se aumentaron las posibilidades de ocurrencia de este riesgo, deberá proceder a informar a la autoridad y tomar las medidas preventivas y correctivas pertinentes frente a ese producto.

Una vez el empresario sepa que uno de sus productos es defectuoso o tiene un indicio serio de que lo es, de acuerdo con lo establecido en el Decreto 1074 de 2015, deberá informar a la autoridad competente designada por el Gobierno Nacional, esto es, a la Superintendencia de Industria y Comercio (SIC).

Ahora bien, lo que se mencionaba líneas atrás, en el sentido de que incluir a todos los bienes muebles en la definición de producto defectuoso resultaba problemático por lo ambiciosa que se presentaba la definición, cobra aún más sentido cuando se piensa que el deber de información de todos los productos 
defectuosos del mercado debe ejercerse ante una única autoridad cuya competencia en materia de consumo es además residual.

Los artículos 11 y 12 del Decreto 4886 de 2011 señalan que en materia de protección al consumidor, que como se ha mencionado abarca el tema de seguridad de producto, la Delegatura para la Protección al Consumidor y la Dirección de Investigaciones de Protección al Consumidor de la SIC serán las áreas competentes para ejercer las actividades de inspección, vigilancia y control de la normatividad vigente.

Por otra parte, el artículo 2 EC indica que las normas contenidas en la ley "son aplicables en general a las relaciones de consumo y a la responsabilidad de los productores y proveedores frente al consumidor en todos los sectores de la economía respecto de los cuales no exista regulación especial, evento en el cual aplicará la regulación especial y suplementariamente las normas establecidas en esta ley".

Así las cosas, resulta importante resaltar que aun cuando existan regímenes especiales, que incluso tratan temas de inocuidad y seguridad en materia de bebidas, alimentos, cosméticos, medicamentos, dispositivos médicos, entre otros, los empresarios que produzcan o comercialicen estos productos también deberán informar a la SIC, sin perjuicio de que deban asimismo adelantar las acciones pertinentes ante la autoridad competente en materia de inspección, vigilancia y control de esos productos. Lo anterior permite concluir que ante todos los escenarios de productos defectuosos, sin perjuicio de la naturaleza del producto, los empresarios deberán ejercer el deber de información ante la SIC.

En ese orden de ideas, el empresario o agente de la cadena de producción o comercialización que conozca de la existencia de un producto defectuoso deberá informar a la SIC su plan de acción frente a esa situación. Este plan de acción deberá contener la siguiente información:

1. Identificación clara, veraz y suficiente del nombre o nombres del bien bajo el cual ha sido comercializado, del tipo de producto, incluyendo la referencia y el número de lote, si fuere el caso, fecha de importación o producción y, de ser posible, las fechas durante las cuales se ha comercializado el bien, número de unidades defectuosas y lugares en los que fue comercializado.

2. Una fotografía, imagen o representación gráfica del bien.

3. En la medida de lo posible, una descripción del tipo de acción que será tomada respecto del bien.

4. Una descripción del defecto y del peligro que se corre con el bien y de las razones para tomar acción sobre éste.

5. En la medida de lo posible, el número y descripción de los daños o víctimas asociadas con el producto, la edad de los afectados o muertos, y, de ser el caso, las fechas anteriores en las cuales tales incidentes o muertes fueron informadas a la Superintendencia de Industria y Comercio. 
6. La identificación de los distribuidores o comercializadores más representativos, con los datos personales de sus responsables y de su ubicación, cuando existan registros.

7. En caso de proceder medidas correctivas, la indicación de las medidas que se tomarán o se han tomado, de ser el caso.

8. En caso de ser procedente, el procedimiento de retoma del bien o de devolución del precio pagado y el nivel de éxito que espera tener con la misma. Los costos que surjan con ocasión de la devolución de bienes deberán ser asumidos por la cadena de distribución y en ningún momento podrán trasladarse a los consumidores ${ }^{35}$.

Una preocupación válida de los empresarios es si dentro de los tres días se debe reportar la totalidad de los puntos enlistados en el decreto. Sin embargo, la interpretación que debe hacerse es que lo que se reporta es un plan de acción que permite a la SIC conocer de qué producto se trata y cuál es la estrategia del empresario para enfrentar la situación, ayudando a su vez a replicar las medidas que pretenda adoptar el agente de la cadena. De ahí que el Decreto 1074 de 2015 disponga en el parágrafo del artículo 2.2.2.52.3 que en todo caso "la Superintendencia de Industria y Comercio podrá solicitar y verificar la información antes mencionada, así como tomar las medidas adicionales necesarias que considere pertinentes", porque ese plan de acción puede ser complementado y modificado por la autoridad a medida que el empresario vaya desarrollando las actividades que escogió estratégicamente.

Adicionalmente, se preguntan en particular los comercializadores si son ellos los que deben reportar a la SIC cuando tengan conocimiento de la existencia de un producto defectuoso, cuando ellos, en la mayoría de los casos, no tienen injerencia en la configuración del defecto. Si el comercializador tiene conocimiento del defecto, debe informarlo de manera inmediata a su distribuidor, al importador y, si es el caso, al productor, sin perjuicio de que informe también a la SIC del hecho de que ha tenido conocimiento del accidente de consumo asociado al producto y que ya lo ha puesto en conocimiento de la cadena de producción y comercialización para que se tomen las medidas pertinentes.

Una vez el agente del mercado tiene conocimiento de la existencia de un producto defectuoso, dentro del plan de acción que tiene que informar a la autoridad debe contemplar de forma obligatoria medidas preventivas frente a los productos despachados y frente a aquellos que aún no se han puesto en circulación.

El artículo 2.2.2.52.4 del Decreto 1074 de 2015 indica que el miembro de la cadena de producción, distribución o comercialización que tenga conocimiento de que un producto tiene un defecto que ha producido o puede producir un evento adverso que atenta contra la salud, la vida o la integridad de las 
personas deberá tomar las medidas apropiadas para prevenir la extensión del daño, y cumplir las siguientes medidas de prevención de manera inmediata:

1. Para el productor o importador:

1.1. Suspender la producción o suspender nuevas órdenes de compra del bien de que se trate, hasta tanto no se cuente con una medida correctiva.

1.2. Informar dentro de un plazo no mayor a tres (3) días calendario a todos sus distribuidores y comercializadores del producto de que se trate.

1.3. Informar a los distribuidores y comercializadores, dentro de sus facultades de gestión o las previstas contractualmente, la suspensión inmediata de la comercialización hasta tanto se tomen las medidas correctivas necesarias.

1.4. Informar a los consumidores sobre el bien implicado por medios idóneos.

1.5. Informar a la Superintendencia de Industria y Comercio.

2. Para el distribuidor y comercializador:

2.1. Suspender la distribución y la comercialización del producto de que se trate.

2.2. Solicitar al productor o al importador la información que se debe suministrar a los consumidores sobre el bien implicado.

2.3. Informar a los consumidores sobre el bien implicado.

2.4. Informar a la Superintendencia de Industria y Comercio.

Adicionalmente, dispone el decreto que el productor, importador, distribuidor o comercializador deberá tomar las medidas necesarias para garantizar que las unidades del producto que no hayan sido despachadas o comercializadas y que estén en su poder no sean puestas en el mercado. Para ello, aislará y marcará el bien de forma tal que asegure de manera efectiva que dichas unidades no serán erróneamente comercializadas. Igualmente, el productor o importador deberá informar a su vez a los distribuidores, comercializadores y puntos de venta final al público sobre la exigencia de aislamiento y marcación de las unidades de productos existentes en su poder. Será responsabilidad del productor o importador establecer el procedimiento para recoger y aislar en condiciones apropiadas las unidades de producto defectuoso y asumir los costos en que se incurra para tal efecto ${ }^{36}$.

Así mismo, el decreto establece qué debe hacer el distribuidor o comercializador frente a los consumidores que tienen en su poder productos defectuosos y cómo debe comunicar las medidas correctivas que ha dispuesto para el producto o que han sido ya indicadas al importador.

Al respecto, dispone el artículo 2.2.2.52.6 del Decreto 1074 de 2015:

... el distribuidor o comercializador que haya expendido a los consumidores finales unidades del producto defectuoso deberá informar directa e inmediatamente a los consumidores acerca de las medidas correctivas dispuestas por el productor 
o importador y, de ser el caso, los medios dispuestos para recoger, aislar, devolver o intervenir los productos. Si no se cuenta con registro o bases de datos para contactar directamente a los consumidores, deberá informar de manera clara y legible, a través de un medio idóneo de comunicación, sobre el carácter defectuoso del producto, las medidas de corrección que sean pertinentes, y, de ser el caso, los medios dispuestos para recoger, aislar y devolver los productos. La intensidad y frecuencia de la publicación en los medios idóneos de comunicación se deberá hacer de forma proporcional al volumen de ventas del producto, el número de consumidores que lo adquirieron y la forma en que se comercializó el producto.

Para efectos de comunicar el recall o las medidas correctivas de las que habla el decreto, se indicó que se debe comunicar a los consumidores usando un medio idóneo de comunicación. La idoneidad del medio escogido deberá estar relacionada con el tipo de consumidor que adquirió el producto que presenta el defecto. Habitualmente se acudía a los diarios de circulación nacional para hacer el anuncio. Sin embargo, las redes sociales (Facebook, Instagram, Pinterest, etc.), así como aplicaciones para teléfonos inteligentes desarrolladas especialmente para temas de seguridad, pueden ser más efectivos frente a los consumidores más jóvenes. Por ejemplo, Pinterest tiene más de 110 millones de usuarios activos, el $71 \%$ son mujeres y el 29\% son hombres, y el $34 \%$ de los usuarios tiene entre 18 y 29 años ${ }^{37}$, lo que hace que sea un medio muy útil para informar en particular a las consumidoras. Este análisis se puede replicar con cualquier otra red social, obteniendo resultados interesantes que permiten concluir que los diarios de circulación nacional no siempre resultan ser el medio idóneo para comunicar un recall.

A continuación dispone el artículo 2.2.2.52.7 del decreto en comento que frente a los productos aislados y recogidos "una vez se tengan identificadas y aisladas las unidades de producto defectuoso, el productor o el importador procederá a destruirlos o, si es posible, a corregir el defecto de tal manera que asegure la eliminación del riesgo para la salud, la vida o la integridad de los consumidores".

Ahora bien, cuando un agente de la cadena de comercialización conozca que uno de sus productos que se encuentra en el mercado es defectuoso y decida guardar silencio, puede ocurrir que la SIC tenga también conocimiento de la existencia de ese producto defectuoso en el mercado y, además de tomar las medidas respectivas para proteger a los consumidores, decida también investigar al empresario por haber incumplido su deber de información poniendo en riesgo la vida, la salud y la integridad del público consumidor, imponiendo las sanciones que indica el Estatuto del Consumidor.

Esta responsabilidad administrativa es de carácter individual, es decir, no se reputa solidaridad alguna entre los agentes de la cadena de producción y 
comercialización. Por lo que se le imputarán cargos por haber vulnerado el derecho a la seguridad e indemnidad de los consumidores y por haber incumplido el deber de información a quien, conociendo o debiendo conocer del defecto de un producto, no realizó ninguna acción para proteger a los consumidores. Esta investigación podrá terminar con la imposición de una sanción en los términos del artículo 61 EC.

Hasta hace un poco más de un año, la única forma que tenía la SIC para enterarse de la ocurrencia de accidentes de consumo asociados a productos era a través de sus agencias pares en otros países, a través de la consulta obligatoria a las redes de alerta de productos inseguros que maneja la Unión Europea ${ }^{38}$ y que tiene Estados Unidos ${ }^{39}$, y a través de la participación activa en la Red de Consumo Seguro y Salud de la OEA que implementó el Sistema Interamericano de Alertas Rápidas ${ }^{40}$.

Sin embargo, por iniciativa de la Delegatura de Protección al Consumidor de la SIC se creó la Red Nacional de Consumo Seguro. Aunque esta red no cuenta con una personería autónoma e independiente, a través de convenios de colaboración la Superintendencia logró que el Ministerio de Salud, el Instituto Nacional de Vigilancia de Medicamentos y Alimentos (INVIMA), el Distrito Capital con su línea de atención de emergencia NUSE, la Sociedad Colombiana de Pediatría y el Instituto Nacional de Medicina Legal y Ciencias Forenses empezaran a compartir información sobre accidentes de consumo para poder determinar si en esos accidentes había estado presente un producto $y$, a su vez, determinar si se trataba de un producto defectuoso que ameritara una acción inmediata.

Ahora, de acuerdo con en el numeral 8 del artículo 59 EC, la Superintendencia podrá

... emitir las órdenes necesarias para que se suspenda en forma inmediata y de manera preventiva la producción o la comercialización de productos hasta por un término de sesenta (60) días, prorrogables hasta por un término igual, mientras se surte la investigación correspondiente, cuando se tengan indicios graves de que el producto atenta contra la vida o la seguridad de los consumidores o de que no cumple el reglamento técnico.

De igual forma, el numeral 4 del artículo 61 EC señala que una de las sanciones que puede imponer la SIC, previa investigación administrativa, es "la prohibición temporal o definitiva de producir, distribuir u ofrecer al público determinados

38 Esta red de alerta de conoce como Rapid Alert System - Rapex. Ver: http://ec.europa.eu/ consumers/consumers_safety/safety_products/rapex/alerts/main/?event=main.listNotifications [consultado el 6 de septiembre de 2016].

$39 \mathrm{http}: / / \mathrm{www} . c p s c . g o v / e n / R e c a l l s /[$ consultado el 6 de septiembre de 2016].

40 https://www.sites.oas.org/rcss/ES/Paginas/alerts/default.aspx [consultado el 6 de septiembre de 2016]. 
productos". Y señala el numeral 5 ibídem que la Superintendencia podrá también ordenar, como sanción, "la destrucción de un determinado producto, que sea perjudicial para la salud y la seguridad de los consumidores".

Así las cosas, con la valiosa información sobre accidentes de consumo asociados a la utilización de productos que se recaba gracias a la colaboración y articulación de las autoridades que hacen parte de la Red Nacional de Consumo Seguro y a las facultades administrativas asignadas en el Estatuto del Consumidor, ante la falta de reacción del empresario aun conociendo el defecto del producto o ante su total desconocimiento de este, SIC, de oficio, realizará la evaluación del riesgo para determinar que el producto es defectuoso, ordenando las medidas a que haya lugar.

El caso más reciente ocurrió con los apuntadores láser. En noviembre de 2015, a través del Ministerio de Salud, se tuvo conocimiento de la ocurrencia de un accidente de consumo en donde un joven había sufrido graves lesiones en un ojo porque un amigo, mientras jugaba, había dirigido el haz de luz del apuntador láser en esa dirección.

Si bien los apuntadores láser que superan la potencia de 1 milivatio tienen estrictas restricciones de comercialización en países como Estados Unidos, Canadá, Francia, Suiza, Reino Unido, Nueva Zelanda, Grecia, Noruega y Australia, por el riesgo que representan para los consumidores, en Colombia este producto circulaba libremente y los agentes del mercado no habían informado o advertido adecuadamente a los consumidores sobre los riesgos a los que se exponían por la indebida utilización del producto. Adicionalmente, se pudo determinar mediante pruebas de laboratorio que los apuntadores láser que se encontraban en el mercado indicaban en su rotulado potencias menores a las que realmente alcanzaban.

Por lo anterior, mediante Resolución 33767 de 2016, publicada en el Diario Oficial n. ${ }^{\circ} 49892$ del 2 de junio de 2016, la Dirección de Investigaciones de Protección al Consumidor ordenó de manera preventiva, mientras se surtía la investigación correspondiente, que se suspendiera inmediatamente la producción, comercialización y distribución de los apuntadores o punteros láser con una potencia mayor o igual a $1 \mathrm{~mW}$ (milivatio), que no fueran para estricta utilización médica, científica, industrial o militar y estuvieran destinados para el exclusivo manejo por parte de expertos y profesionales.

Surtida la investigación, mediante Resolución 57151 del 29 de agosto de 2016 $6^{[41]}$, publicada en Diario Oficial n. ${ }^{\circ} 49982$ del 31 de agosto de 2016, la Dirección de Investigaciones de Protección al Consumidor prohibió

41 http://www.sic.gov.co/drupal/recursos_user/documentos/normatividad/Resoluciones/2016/ Resolucion_57151_2016.pdf 
... de manera inmediata y definitiva la COMERCIALIZACIÓN Y TODA PUESTA A DISPOSICIÓN a los consumidores bajo cualquier modalidad (presencial, o a través de cualquier otro tipo de venta no tradicional o a distancia) del producto denominado: "APUNTADOR LÁSER con potencia de salida mayor o igual $(\geq)$ a un (1) milivatio $(\mathrm{mW})$ ", "PUNTERO LÁSER con potencia de salida mayor o igual $(\geq)$ a un (1) milivatio $(\mathrm{mW})$ ", "SEÑALIZADOR LÁSER con potencia de salida mayor o igual $(\geq)$ a un (1) milivatio $(\mathrm{mW})$ ", descrito en el numeral 8.1 de la parte motiva de esta resolución, con independencia de su marca y referencia, salvo que su utilización o destinación se circunscriba a fines médicos, científicos (comprendidas las actividades de astronomía), industriales o militares, y estén destinados para el exclusivo manejo por parte de expertos y profesionales, estableciendo que para la comercialización de estos productos deberá llevarse un registro por cada dispositivo vendido mediante el cual se identifique: (i) fabricante del producto (procedencia), (ii) proveedor del producto, (iii) potencia de salida expresada en milivatios $(\mathrm{mW})$ y/o clase del producto de acuerdo a las clasificaciones de la FDA (I, IIa, II, IIIa, IIIb y IV) y del CEI $(1,1 \mathrm{M}, 2,2 \mathrm{M}, 3 \mathrm{R}, 3 \mathrm{~B}$ y 4), (iv) longitud de onda (expresada en nanómetros), (v) copia de la identificación del adquiriente del puntero, (vi) dirección del domicilio del adquiriente y (vii) copia del carnet o documento que acredite la destinación científica, industrial, médica o militar del producto.

De igual forma, se precisa en la resolución:

... mediante la presente orden no sw restringe el mercado de los productos con tecnología láser así como tampoco los destinados en espectáculos de entretenimiento de carácter público y/o privado, lo anterior, sin perjuicio de advertir que en estas hipótesis los dispositivos deben ser manipulados por personal que detente el conocimiento sobre las precauciones e instrucciones para su utilización así como de las consecuencias de las lesiones causadas por este dispositivo en los ojos y piel de los espectadores o de sí mismo. Si este dispositivo es utilizado profesionalmente, y sus haces de luz difractados son mayores o iguales $(\geq)$ a un (1) milivatio $(\mathrm{mW})$, la empresa o persona natural que preste este servicio deberá garantizar que el operador se encuentre presente y en control del dispositivo durante todo el tiempo que éste permanezca conectado al circuito eléctrico o que la luz láser esté encendida, a efectos de evitar que cualquiera de éstos haces de luz impacte directamente al público.

También se puede mencionar el noticioso caso de las mini gelatinas. En este evento, prestigiosos pediatras pusieron en conocimiento de la SIC la ocurrencia de varios accidentes de consumo en donde menores de edad habían visto afectada de manera seria su salud por haber ingerido este alimento.

Luego de realizar la respectiva evaluación del riesgo y de verificar que este producto se encontraba prohibido en otros países, mediante Resolución 79980 de 2015 se prohibió de manera inmediata y definitiva la "PRODUCCIÓN, IMPORTACIÓN, COMERCIALIZACIÓN Y TODA PUESTA A DISPOSICIÓN del producto denominado: 
'MINI GELATINA' 'GEL SABORIZADO DE GELATINA' 'GELATINA VARIEDAD CON FRUTA' 'MINI GELATINA DE FRUTA' 'MINI FRUITY GELS' 'MINI FRUIT JELLY' o 'MINI FRUIT BITES'".

Dispuso la Superintendencia en la mencionada resolución que, "ante la ineficacia de las advertencias existentes, y debido a que no existe información o alertas que sean capaces de mitigar el riesgo identificado por esta Dirección, la medida de control de mercado necesaria e idónea para mitigar el riesgo que representa el producto objeto de análisis, es retirar el producto 'MINI GELATINAS' del mercado, a fin de proteger la salud, la integridad física y la vida de los consumidores".

Continúa explicándose en la resolución:

... luego de efectuar un pormenorizado estudio sobre los riesgos que entraña el producto, y de analizar de manera documentada y suficiente los accidentes de consumo relacionados con las MINI GELATINAS", encuentra que la composición física del producto genera riesgos que no pueden ser mitigados con información o advertencias, lo que conduce a concluir que para mitigar tales riesgos resulta inexorable retirar el producto del mercado, el cual no podrá producirse, importarse, comercializarse, ni ponerse a disposición de los consumidores hasta tanto no se modifiquen las características físicas del mismo, tales como su tamaño, forma, consistencia, textura y modo de uso, pues dadas las características físicas que hoy tiene, los riesgos de que se concreten lesiones serias en la salud de los consumidores son sumamente altos.

Así mismo, señala:

... la eventual comercialización de los geles saborizados tiene que realizarse de tal forma que no relacione las "MINI GELATINAS" con las gelatinas corrientes, las cuales tienen una composición y unas propiedades sumamente diferentes, cuya relación o asociación genera confusión y engaño a los consumidores que tienen profundas implicaciones en materia de seguridad, pues hacen pensar a consumidores medios que los geles saborizados pueden ser entregados a menores, cuando estos son los consumidores más vulnerables frente al referido producto por no contar con las herramientas físicas necesarias para ejercer un mejor control de las "MINI GELATINAS" dentro de la cavidad oral, y por no tener las capacidades para poder reaccionar de mejor manera frente a un episodio de asfixia.

De igual forma, se explica en la resolución:

... los componentes químicos que se vayan a utilizar en este tipo de productos, no pueden contener aditivos que generen una alta insolubilidad del producto, aspecto que constituye, en cuanto a su composición química, uno de los elementos que representa mayores riesgos para la salud, pues conduce a que si el producto llega a pasar la boca para alojarse en la faringe, el mismo no pueda deshacerse de manera pronta, sino que queda intacto causando la asfixia. 
Señala luego la Superintendencia, en el citado acto administrativo:

... las anteriores consideraciones no constituyen una orden sobre el rediseño del producto, pues son los productores e importadores quienes se encuentran en mejores condiciones para efectuar la reingeniería más apropiada sobre las mercancías que introducen en el mercado. Por el contrario, se trata de una exposición de las consideraciones que tuvo en cuenta esta Dirección para prohibir este específico producto, en aras de advertir a los productores sobre los elementos que tornaron las "MINI GELATINAS" inseguras, con miras a que puedan hacer las variaciones y los ajustes que consideren pertinentes para eliminar de manera efectiva los riesgos identificados por esta autoridad.

Además de las decisiones sobre los apuntadores láser y las mini gelatinas, que son el resultado de datos que se han obtenido acerca de accidentes de consumo que ocurrieron en Colombia, se pueden mencionar los siguientes casos.

Mediante Resolución 67541 del 1 de noviembre de 2012, la Superintendencia concluyó que en ciertos casos las esferas acuáticas presentan riesgos irrazonables para la salud o integridad de los consumidores, porque su uso conlleva un riesgo potencial de asfixia, ahogamiento, lesiones a causa de golpes, afectaciones a la salud por falta de asepsia y, en los niños, episodios de conmoción, pánico y zozobra ${ }^{42}$.

Frente a las máscaras de disfraces para niños, la Superintendencia, mediante Resolución 33 del 9 de enero de 2013, concluyó que el uso de este producto conlleva un riesgo potencial de asfixia, especialmente cuando por su diseño se cubra enteramente la cabeza y el rostro, no cuente con orificios que permitan ejecutar el proceso de respiración en forma natural, y tenga un tipo de ajuste o amarre que comprometa su retiro fácil en caso de necesitarse oxígeno por el usuario ${ }^{43}$.

Por otra parte, tratándose de juguetes y baterías para juguetes, la Superintendencia prohibió, mediante Resolución 11638 del 20 de marzo de 2013, la producción, distribución y comercialización de todo juguete, incluido el control remoto con el que opere, que no cuente con un sistema de seguridad que restrinja a los niños el fácil acceso al compartimiento de las pilas o baterías. Las pilas o baterías conllevan un riesgo potencial de asfixia, lesiones internas por quemaduras químicas y muerte por envenenamiento tóxico ${ }^{44}$.

Con relación a los vehículos cuatrimotos, mediante Resolución 37886 del 25 de junio de 2013 la Superintendencia concluyó que las cuatrimotos que

42 http://www.sic.gov.co/drupal/masive/datos/resoluciones_consumo_seguro/DEFINITIVA_ESFERAS.pdf

$43 \mathrm{http}: / /$ www.sic.gov.co/drupal/masive/datos/resoluciones_consumo_seguro/MASCARAS.pdf

$44 \mathrm{http}: / /$ www.sic.gov.co/drupal/sites/default/files/normatividad/b178d619-258c-464e-854c95b2f99a 104a 
funcionan con combustible no son un juguete. Por tanto, prohibió al comerciante investigado cualquier forma de publicidad o mecanismo de comercialización en que se ofrezcan los vehículos cuatrimotos o mini-cuatrimotos como juguetes, sin excepción alguna e independiente de su diseño y dimensiones ${ }^{45}$.

Igualmente, mediante Resolución 53956 del 10 de septiembre de 2013, la Superintendencia declaró que el producto "vela pirotécnica para uso con fines de diversión / vela pirotécnica" y aquellos artículos de similares características, independientemente de la manera como se denominen en el mercado y de que se verifique o no en su contenido la presencia de pólvora, son productos pirotécnicos. En consecuencia, su uso, almacenamiento y transporte se encuentra regulado por normas especiales toda vez que conlleva un riesgo de quemaduras corporales e incendio. Del mismo modo y dependiendo del producto, la migración de elementos pesados hace de estas velas un producto tóxico ${ }^{46}$.

De igual forma, mediante Resolución 38973 del 28 de junio de 2013, la Superintendencia prohibió la comercialización u ofrecimiento al público en general de toda "cortina" y "persiana" de uso doméstico en la que se utilicen, entre otros, cordones, cordeles, cuerdas y cadenas de accionamiento como "tipo de ajuste" y no cuenten con un dispositivo de seguridad que evite que el sobrante del elemento de atar, cualquiera que este sea, cuelgue libremente al alcance de los niños en forma de circunferencia, bucle o anillo. Este dispositivo de seguridad se ordenó para mitigar el riesgo de estrangulamiento asociado a las cuerdas que cuelgan libremente en las cortinas ${ }^{47}$.

Ahora bien, si un empresario desatiende estas órdenes generales en materia de seguridad de producto, podrá ser igualmente investigado y sancionado atendiendo lo dispuesto en el artículo 61 EC.

Sobre la base de lo hasta aquí expuesto se puede concluir que la seguridad de los productos de consumo representa una obligación compleja a cargo de los empresarios que supera las tradicionales obligaciones de informar y de evitar la publicidad engañosa.

Exigir la seguridad de los productos de consumo garantiza que la salud y la integridad de los consumidores estén salvaguardadas, y contar con normas en el ordenamiento jurídico colombiano en esta materia acerca al país a los exigentes estándares que se aplican a nivel internacional, impidiendo a su vez que, por la laxitud de la regulación, ingresen al territorio productos que por su inseguridad o defectuosidad han sido rechazados en otras latitudes.

45 http://www.sic.gov.co/drupal/sites/default/files/files/R_\%2037886-13\%20ORDEN\%20DEFINITIVA \% 20PARTICULAR\%20CUATRIMOTOS.pdf

$46 \mathrm{http}: / / \mathrm{www}$. sic.gov.co/drupal/masive/datos/resoluciones_consumo_seguro/Resolucion_53956_FONDO.pdf

47 http://www.sic.gov.co/drupal/sites/default/files/files/R_\%2038973-13\%20ORDEN\%20DEFINITIVA\%20CORTINAS\%20Y\%20PERSIANAS.pdf 


\section{BIBLIOGRAFÍA}

\section{DOCTRINA}

Caycedo Espinel, Carlos Germán. "Esquema de la responsabilidad civil en el derecho de protección al consumidor en Colombia", en Mateo SÁnChez García (coord.), La responsabilidad civil en el nuevo Estatuto del Consumidor, Bogotá: Universidad Jorge Tadeo Lozano, 2013, pp. 91-112.

Cepeda Espinosa, Manuel José. "La responsabilidad del fabricante por productos defectuosos (en el derecho comparado y la legislación colombiana)", Revista de Derecho Privado, n. ${ }^{\circ}$, Universidad de los Andes, 1986, pp. 33-74.

Cerami, P.; Di Porto, A., Petrucci, A. Diritto commerciale romano: profilo storico, Torino: Giappichelli, 2004.

De la Cruz Camargo, Dionisio Manuel. "La garantía legal y la responsabilidad por producto defectuoso en el nuevo Estatuto del Consumidor", Con-texto, Universidad Externado de Colombia, 2012, pp. 11-35.

EsPinOSA AprÁEZ, BREndA. "La responsabilidad por producto defectuoso en la Ley 1480 de 2011. Explicación a partir de una obligación de seguridad de origen legal y constitucional", Revista de Derecho Privado, n. ${ }^{\circ} 28$, Universidad Externado de Colombia, 2015.

Munar Cadena, Pedro Octavio. "La responsabilidad por productos. Los grandes hitos de su evolución", en J. M. Gual Acosta, Derecho del consumo. Problemáticas actuales, Bogotá: Jurídicas Gustavo Ibáñez, 2013, pp. 173-211.

Owen, David y Davis, Mary. Products Liability and Safety, Minnesota: West Academic Publishing, 7. ${ }^{\text {a }}$ ed., 2015.

Rodríguez Carrión, José Luis. "La responsabilidad civil por los daños causados por productos defectuosos", Revista General de Derecho, Valencia, 2000.

Staern, Denis W. An introduction to product liability. Disponible en: http://www.marlerclark. $\mathrm{com} / \mathrm{pdfs} /$ intro-product-liability-law.pdf [consultado el 6 de septiembre de 2016].

TABAKian, Marcela. "Evolución de la responsabilidad del fabricante en Estados Unidos y su influencia en el derecho comparado", Revista de Derecho de la Universidad de Montevideo, 26, 2014.

TAmayo Jaramillo, JaVier. "La responsabilidad civil en el nuevo Estatuto del Consumidor". Disponible en: http://www.utadeo.edu.co/files/node/publication/field_attached_file/pdf-la_responsabilidad_civil_-web-_pag._16.pdf [consultado el 9 de septiembre de 2016]. 
Tamayo Jaramillo, Javier. Responsabilidad por producto defectuoso, Bogotá: Legis, 2016.

Velandia Castro, Mauricio. "Acciones derivadas de las fallas en los productos (garantía legal, comercial y producto defectuoso)", en Perspectivas del derecho del consumo, Bogotá: Universidad Externado de Colombia, 2013, p. 516.

Villalba Cuéllar, Juan Carlos. Introducción al derecho del consumo, Bogotá: Universidad Nueva Granada, 2012.

Villalba Cuéllar, Juan Carlos. "La responsabilidad por producto defectuoso en el derecho colombiano", Civilizar, vol. 14, n. ${ }^{\circ}$ 27, Universidad Sergio Arboleda, 2014, pp. 22-24.

Zalamea Lechtman, Carolina. La responsabilidad civil derivada de los productos defectuosos, Colección de Maestrías n. 4, Bogotá: Pontificia Universidad Javeriana, Facultad de Ciencias Jurídicas y Grupo Editorial Ibáñez, 2014.

\section{PÁGINAS WEB DE INTERÉS}

https://www.linkedin.com/pulse/pinterest-2016-statistics-110million-monthly-usersivonne-teoh [consultado el 19 de septiembre de 2016].

http://ec.europa.eu/consumers/consumers_safety/safety_products/rapex/alerts/ main/?event=main.listNotifications [consultado el 6 de septiembre de 2016].

http://www.cpsc.gov/en/Recalls/ [consultado el 6 de septiembre de 2016].

https://www.sites.oas.org/rcss/ES/Paginas/alerts/default.aspx [consultado el 6 de septiembre de 2016].

https://www.accc.gov.au/business/treating-customers-fairly/product-safety\#productsafety-regulation [consultado el 6 de septiembre de 2016].

\section{JURISPRUDENCIA COLOMBIANA}

Corte Suprema de Justicia, Sala de Casación Civil. Sentencia del 30 de abril de 2009, M.P.: Pedro Octavio Munar Cadena, ref. 258993193992199900629.

\section{JURISPRUDENCIA EXTRANJERA}

MacPherson v. Buick Motor Co. 217 N.Y. 382, 111 N.E. 1050 (1916). Disponible en: https:// www.nycourts.gov/reporter/archives/macpherson_buick.htm [consultado el 6 de septiembre de 2016].

Cronin v. J.B.E Olson Corp. Disponible en: http://scocal.stanford.edu/opinion/croninv-jbe-olson-corp-32939) [consultado el 6 de septiembre de 2016]. 
Actos administrativos de la Superintendencia de Industria y Comercio

Concepto de la Oficina Jurídica de la Superintendencia de Industria y Comercio, rad. 13-040240. Disponible en: http://www.sic.gov.co/drupal/sites/default/files/ normatividad/Concepto_13-40240.pdf [consultado el 6 de septiembre de 2016].

Resolución 57151 de 2016.

Resolución 79980 de 2015.

Resolución 33 de 2013.

Resolución 67541 de 2012.

Resolución 11638 de 2013.

Resolución 37886 de 2013.

Resolución 53956 de 2013.

Resolución 38973 de 2013.

NORMATIVIDAD COLOMBiANA

Constitución Política de la República de Colombia.

Decreto 1074 de 2015.

Decreto 4886 de 2011.

Decreto 679 de 2016.

Ley 1480 de 2011.

NORMATIVIDAD EXTRANJERA

Código de Defensa del Consumidor del Brasil.

Directiva 85/374/CEE.

Directiva 92/59/CEE.

Texto refundido de la Ley General de Defensa de los Consumidores y Usuarios.

United States Consumer Product Safety Act (Codified at 15 usc 2051-2089) Public Law 92-573; 86 Stat. 1207, Oct. 27, 1972. 